\title{
Participação em organizações sociais do ramo de agroindústria familiar no estado de Rondônia: uma percepção de incentivos mútuos
}

\author{
Participation in Social organizations of family farming sector In the state of \\ Rondônia: a perception of mutual incentives
}

\begin{abstract}
Resumo
O presente artigo tem como objetivo identificar a motivação para participar em organizações socias do ramo de agroindústria familiar no estado de Rondônia. Parte-se da análise das perspectivas individuais e coletivas, de forma unificada, reconhecendo como importante e natural, pois mesmo buscando benefícios próprios pode se contribuir para um todo. O modelo de organizações sociais é capaz de desenvolver pessoas e arranjos produtivos locais, considerando o senso de comunidade, objetivos e valores compartilhados. A partir destes construtos foi realizado uma pesquisa de campo sobre organizações sociais nas agroindústrias familiares do estado de Rondônia, as quais vêm se desenvolvendo em função de incentivos governamentais, no entanto, neste segmento, a cultura e os princípios do cooperativismo são incipientes. Desta forma, analisou quais os fatores que os membros de organizações sociais consideram relevantes para participação e assim conseguir ampliar as possibilidades de crescimento.
\end{abstract}

Palavras-chave: Organizações sociais, participação coletiva, agroindústria familiar, Rondônia - Amazônia.

\begin{abstract}
This article aims to identify the motivation to participate in companies in the family farming sector in the state of Rondônia. It starts from the analysis of individual and collective perspectives, in a unified way, recognizing it as important and natural, because even seeking own benefits, it is possible contribute to a whole. The model of social organizations is capable of developing people and organizing local products, considering the sense of community, objectives and shared values. Based on these constructs, a field research was realized on social organizations in family farming in the state of Rondônia, that are developing themselves from govermment incentives, however, in this segment, the culture and the principles of cooperation are incipients. In this way, it was analyzed the factors that members of social organizations consider relevant for participation and, therefore, increase the possibilities of growth.
\end{abstract}

Keywords: Social organizations, collective participation, family agroindustry, Rondônia - Amazon.

Paula Almeida Brito ${ }^{\mathrm{I}}$, Mariluce Paes De Souza ${ }^{\mathrm{II}}$, Daniel Menéndez Llerena ${ }^{\mathrm{III}}$, Tomás Daniel Menendez Rodrigues $^{\mathrm{IV}}$

${ }^{\text {I } U n i v e r s i d a d e ~ F e d e r a l ~ d e ~ R o n d o ̂ n i a . ~ p a u l a a b 18 o 6 @ g m a i l . c o m ~}$

${ }^{\mathrm{II}}$ Universidade Federal de Rondônia. mariluce@unir.br

III Universidade Federal de Rondônia. dmenendezllerena@gmail.com

IV Universidade Federal de Rondônia. tomas@unir.br 


\section{Introdução}

As organizações sociais sem fins lucrativos, ancoradas no Terceiro Setor, porém ainda difusas, são conhecidas por várias denominações, como: "setor da caridade", "setor independente", "setor voluntário", "organizações não-governamentais", "economia social”, "filantropia" entre outros

(ALVES, 2002). Estas organizações possuem diversos tipos, como: Associações, Mútuas, Cooperativas e Fundações, que atuam em vários segmentos da economia.

Outra característica dessas organizações atrela-se a atuação das pessoas no coletivo, que se associam por um objetivo comum, incorporando princípios mútuos, tão desejosos neste século, que estão preocupados com os aspectos sociais e ambientais, além dos aspectos econômicos. Isto as torna exemplos de organizações que podem responder aos anseios de sustentabilidade e de construir uma sociedade melhor.

A participação dos membros é uma das estratégias chave para prosperar nesta perspectiva organizacional (BIRCHALL; SIMMONS, 2004), possibilitando entender são as motivações que levam as pessoas a se associarem, participarem, permanecerem nas organizações sociais, até se desassociar. Para entender essas motivações, este trabalho apoia-se na Teoria dos Incentivos Mútuos (Mutual Incentives Theory), que compreende o pensamento individual e coletivo, buscando na natureza do homem racional e egoísta, que vivência o capitalismo, ser desperto para cooperar, e a viver melhor em sociedade.

Para identificar tais atributos a pesquisa foi aplicada na agroindústria familiar, que como elo importante do agronegócio contribui para a economia do estado de Rondônia. Embora as fontes oficiais anunciem que a agroindústria ainda tenha pequena adesão à cultura do cooperativismo ou outra modalidade de organização social, esta é representativa para o Estado, como também, demonstra a importância de estudar o setor. Este estudo tem como objetivo identificar a motivação para participar em organizações socias do ramo de agroindústria familiar no estado de Rondônia e continuar ativos como membros no cenário onde o estado é promissor neste segmento, mas as organizações sociais ainda são tímidas.

O presente artigo divide-se em seis seções. A primeira abrange o referencial teórico com o histórico, conceito e diversidades das organizações sociais e multi atores. A segunda refere-se à metodologia utilizada para efetivação da pesquisa. A terceira seção apresenta dados sobre a agroindústria familiar de Rondônia e a quarta sessão explana os resultados da pesquisa de campo e a inerente discussão com o aporte teórico considerado. A última seção trata das considerações finais dos autores acerca do conteúdo deste artigo.

\section{Referencial Teórico}

A nova economia institucional foi mais que uma mudança econômica, foi também uma mudança sociológica. Para se desvencilharem de organizações governamentais e jurídicas, essas pessoas desassistidas por estes modelos se unem buscando solucionar problemas que foram impostos pela eficiência e competição econômica e ainda a má distribuição da renda (GRANOVETTER, 1992). Criando nos anos de 1970 um terceiro setor na economia, para definir uma atividade de natureza não-governamental, não-mercantil e sem fins lucrativos, denominada economia social (ALVES, 2002).

Explicando a lacuna dos setores, temos o primeiro setor representado pelo mercado de bens privados, que são imputados da desigualdade na distribuição de renda. O segundo setor é representado pelo governo de bens públicos, responsáveis pela assistência social dos mais desfavorecidos, mas que é ineficiente por não conseguir atender a demanda. O terceiro setor busca atender os mais desfavorecidos com a ação conjunta dos insatisfeitos com as práticas de mercado (BIRCHALL, 2000). No Quadro 1 está representado os setores com os seus agentes e finalidades. 
Quadro 1: Setorização dos Agentes por Finalidades

\begin{tabular}{|c|c|c|}
\hline AGENTES & FINALIDADE & SETOR \\
\hline Privados & Privada & Mercado \\
Públicos & Pública & Estado \\
Privados & Pública & Terceiro Setor \\
\hline
\end{tabular}

Fonte: ALVES, 2002 p. 7.

Segundo o Banco Mundial (1997), o Terceiro Setor se caracteriza como organizações privadas que realizam atividades voltadas para reduzir o sofrimento humano, promover o interesse dos pobres, proteger o meio ambiente, prover serviços sociais básicos e desenvolver. Esse setor é bem amplo e engloba várias categorias de organizações sociais.

Organizações que tem o objetivo centrado nas pessoas, gerando valor para seus membros e suas comunidades, associando as pessoas da classe trabalhadora para melhorar suas condições (BIRCHALL, 1995). Muito mais do que gerar negócios, organizações sociais tem um papel decisivo no contexto da economia social, impulsionando a promoção do emprego, do bem-estar social, do desenvolvimento local e a inclusão dos mais desfavorecidos (CAEIRO, 2008).

Organizações sociais engloba vários modelos, podendo ser divididos sem fins lucrativas, híbridas, voluntárias ou de caridade (BIRCHALL, 1995) e subdividida em cooperativas, mútuas, associações e fundações (CAEIRO, 2008), que são termos quase sinônimos, mas que possuem suas particularidades. Pequenas particularidades diferenciam esses modelos, onde as cooperativas são organizações sociais com o sistema aberto, concernente por aceitar clientes que não são membros, já as mútuas são consideradas sistema fechado, porque a negociação é somente com os próprios membros. As associações possuem termos mais amplos e sem regras universais para se diferenciam (BIRCHALL, 2011) e as fundações são caracterizadas como filantrópicas. Todos esses modelos podem atuar em diferentes setores do mercado, como agropecuário, saúde, crédito, educação, habitacional, consumo entre outros. Entre esses modelos, cooperativas é o segmento que mais se desenvolve.

\subsection{Cooperativas}

A cooperação é uma forma de trabalhar em conjunto com outras pessoas que possuem necessidades ou problemas semelhantes para assim reunir recursos financeiros e humanos (PARNELL,2001). Cooperação baseia-se no sentimento de valor mútuo dos seus participantes e não em uma regra geral para todas as pessoas ou uma visão orgânica da sociedade toda (PUTMAN, 1994). A simples atividade ou sentimento de cooperação não constitui uma cooperativa.

O movimento e formalização de cooperativas começaram no início do século XIX, quando a marginalização do trabalho ao capital deflagrou grandes movimentos sociais no seio da Revolução Industrial, tendo como grande propagador dos ideais cooperativistas, Robert Owen (1771-1858), que foi considerado um dos líderes do "socialismo utópico" pregando ser a indústria em si benéfica, ao baratear os bens de consumo, no entanto, ela deveria ser colocada sob o controle dos trabalhadores e os resultados do trabalho em comum, repartidos igualmente, propondo assim que se formassem aldeias cooperativas ao redor das fábricas, onde os meios de produção seriam geridos coletivamente (SINGER, 2000).

O "owenismo" tornou-se um movimento de massas na Inglaterra, tendo Owen assumido a liderança de lutas operárias e orientado os sindicatos a formar cooperativas de produção, assim, "o surgimento do cooperativismo está estreitamente relacionado com a origem do sindicalismo." (MISI, 200o, p. 72). Mas o grande marco do movimento cooperativista foi a constituição da cooperativa de 
Rochdale em 1844 na Inglaterra, fundada por 28 tecelões, chamada de "Sociedade dos Pioneiros Equitativos de Rochdale" (Rochdale Society of Equitable Pioneers), que eram operários militantes owenistas (SINGER, 2000).

O sucesso alcançado pela Cooperativa de Rochdale foi fundamental para disseminação do cooperativismo em torno das ideias que nortearam a sua atuação, se espalhando para outros países, crescendo e amadurecendo o movimento cooperativista, até a formação da Aliança Cooperativa Internacional (ACI), em 1895, em Londres, para orientar a atuação das cooperativas de forma unificada mundialmente (MISI, 2000).

A ACI é o órgão máximo de representação do cooperativismo e guardiã da Declaração sobre Identidade Cooperativa, onde está inserido o conceito, os valores e princípios das cooperativas, preservando a origem de Rochdale e se adaptando ao mercado globalizado, sendo estes alterados em 1995. Na Identidade Cooperativa, o conceito de cooperativas é:

Uma associação autônoma de pessoas voluntariamente unidas para atender às suas necessidades e aspirações comuns em questões econômicas, sociais e culturais por meio de uma empresa de gestão democrática e de propriedade conjunta (ACI, p. 23.1998).

Segundo a ACI, as cooperativas têm como bases os valores da honestidade, atitude receptiva, responsabilidade social, respeito pelos outros, autoajuda, autorresponsabilidade, democracia, igualdade, equidade e solidariedade. Além dos 10 valores declarados, possui 7 princípios, que são:

1. Associação voluntaria e aberta - aberta a todas pessoas capazes de usar seus serviços e que desejam aceitar as responsabilidades da associação, sem discriminação de gênero, social, racial, política ou religiosa.

2. Controle democrático dos membros - controladas por seus membros, que estão ativamente envolvidos no estabelecimento de suas políticas e na tomada de decisões. Todo homem e mulher que desempenha a função de representantes selecionados é responsável perante os membros. Nas cooperativas primárias, os membros têm o mesmo direito de voto (um membro, um voto), enquanto em outros níveis das cooperativas eles também são organizados de maneira democrática.

3. Participação econômica dos parceiros - contribuem igualmente para o capital da cooperativa e controlam-na democraticamente. Pelo menos parte do capital é geralmente propriedade comum da cooperativa. Os membros normalmente recebem remuneração limitada, se houver, sobre o capital subscrito como condição de associação. Os parceiros alocam, sobre o capital subscrito como condição de associação. Os parceiros alocam os benefícios para qualquer uma das seguintes finalidades: desenvolver sua cooperativa, possivelmente através da criação de reservas, sendo uma parte indivisível delas; beneficiar os membros proporcionalmente às suas transações com a cooperativa; e apoiar outras atividades aprovadas pela associação.

4. Autonomia e independência - são organizadas autônomas de autoajuda controladas por seus membros. Se eles chegarem a acordos com organizações externas, incluindo governos, ou aumentarem seu capital de fontes externas, o farão de maneira a garantir o controle democrático de seus membros e manter a autonomia da cooperativa.

5. Educação, treinamento e informação - oferecem educação e treinamento a seus membros, representantes eleitos, diretores e funcionários, para que possam contribuir 
efetivamente para o desenvolvimento de suas cooperativas. Eles informam o público em geral - principalmente jovens e líderes de opinião - sobre a natureza e os benefícios da cooperação.

6. Cooperação entre cooperativas - servem seus membros de maneira mais eficaz e fortalecem o movimento cooperativo, trabalhando juntos por meio de estruturas locais, nacionais, regionais e internacionais.

7. Sensação de comunidade - trabalham para o desenvolvimento sustentável de suas comunidades através de políticas aprovadas por seus membros.

Schulze (1987) afirma que as cooperativas assumem essencialmente, devido aos seus princípios doutrinários, a dupla função de associação (enquanto reunião de pessoas) e de empresa (enquanto reunião de capital). Por outro lado, os cooperados também assumem o duplo papel de proprietário e usuário do empreendimento. Nas cooperativas de trabalhadores assumem também a dupla qualidade de membro e usuário ou membro-cooperador, pois ninguém pode ser membro sem assumir o compromisso de participar da cooperativa, como também não pode beneficiar dos serviços sem a qualidade de membro, sendo essa a definição de mutualidade (LEVI, 1998).

Cooperativas em geral são satisfatórias para o membro, porque reduz diversos custos, aumenta a competitividade, oferecendo igualdade de oportunidades, divisão dos rendimentos além da propriedade do negócio. Mas o desmembramento da propriedade também é carregado de dificuldades, principalmente em relação à tomada de decisão coletiva, outro fator complexo é o propósito da participação, tais como afinidade, interesse ou disponibilidade. Assim mesmo esse modelo representa uma grande parte na economia, principalmente dos países desenvolvidos (BIRCHALL, 2011). O fator diferencial dessas organizações são as partes interessadas e suas relações, sendo multi-stakeholding por interagir com três tipos de partes interessadas - consumidores, produtores e empregados (BIRCHALL; SIMMONS, 2004), chamados de multi atores.

\subsection{Multi Atores}

Multi atores nas organizações sociais podem ser compreendidos no engajamento de três classes, que são as principais partes interessadas: produtores, consumidores e empregados (BIRCHALL, 2011) e estes podem exercer múltiplos papéis como de direção, de funcionário e/ou associado, para assim participar e administrar. Porém, a participação é influenciada por comportamentos que se opõem em duas linhas de pensamento.

As ciências sociais dividem essas linhas de pensamentos: em homo economicus, associada a Adam Smith, e homo sociologicus, associada a Emile Durkheim, o homo economicus se orienta pela racionalidade do ser humano que deseja maximizar seus lucros e eliminar suas perdas, movidos pela competição e recompensas já o homo sociologicus se orienta pelas normas sociais onde se comportam de forma a serem reconhecidos e aceitos dentro da sociedade ou grupo, e assim norteada a cooperar (INDALECIO, 2010).

Nesta dialética, Birchall e Simmons (2004) desenvolveram a teoria dos incentivos mutuais (mutual incentives theory), nas perspectivas individualista e coletivista, para explicar a participação dos membros através dos dois comportamentos: o racional (competitivo) e o social (cooperativo).

A abordagem individualista é desenvolvida a partir da teoria da troca social, que defende que as interações humanas são transações que procuram maximizar as recompensas (ganhos) e minimizar os custos (perdas), e assim existe a tendência a manter aquelas relações nas quais os ganhos excedem os custos e terminar aquelas em que os custos são maiores que os ganhos.

Na Figura 1, a abordagem individualista, ilustra a participação a partir da utilização de fatores com influência positiva e negativa. 


\section{Figura 1. Abordagem Individualista}

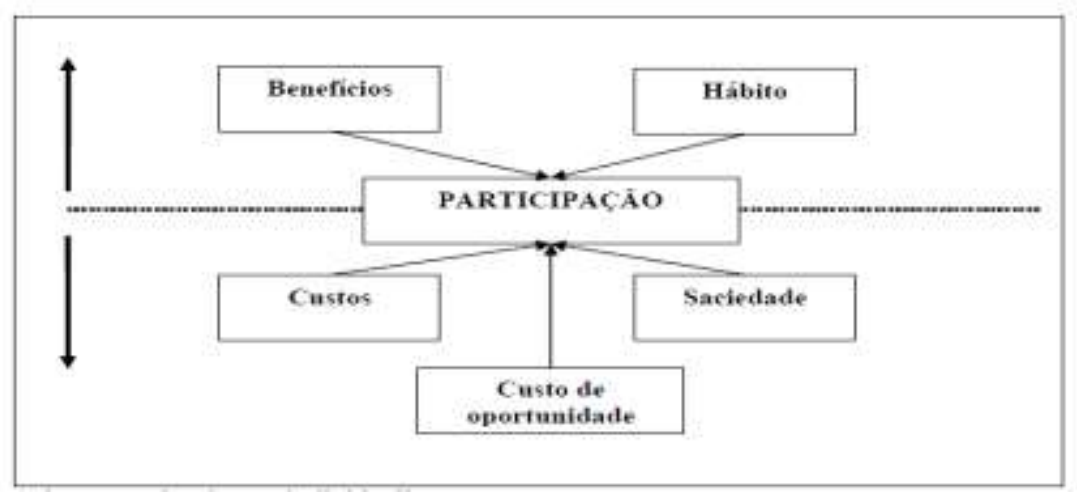

Fonte: BIRCHALL E SIMMONS, 2004 p. 470.

Os benefícios e hábito consistem nos fatores positivos, os quais estão detalhados a seguir:

$>$ Benefícios são subdivididos em internos, aqueles que são percebidos subjetivamente, como o prazer, autoconfiança, sensação de dever cumprido; e os externos, $a$ autopromoção que atrela-se a vida social, o reconhecimento dos outros, recompensa financeira e profissional.

> Hábito é entendido como costume ou comportamento espelhado.

Os custos de oportunidade e a saciedade são os fatores negativos, descritos na sequência:

> Custos é a percepção de dispêndios financeiros, tempo, esforço e relações.

> Custos de oportunidade representam as perdas decorrentes da renúncia, ou seja, o que se deixou de ganhar com outra escolha por ter feito a escolha de participar, podendo ser o trabalho, família e lazer.

Saciedade é uma indiferença pela satisfação e resultado já alcançado.

Por outro lado a coletivista é desenvolvida a partir da teoria da cooperação social que pode ser explicada como a forma que os indivíduos, que visam satisfazer seus próprios interesses, podem cooperar entre si, sem ajuda de uma autoridade central que os forcem a isto. A partir desta teoria, Simmons e Birchall (2004) sintetizaram três fatores do ponto de vista coletivo que podem levar um indivíduo a participar, conforme visto na Figura 2. 
Figura 2. Abordagem Coletivista

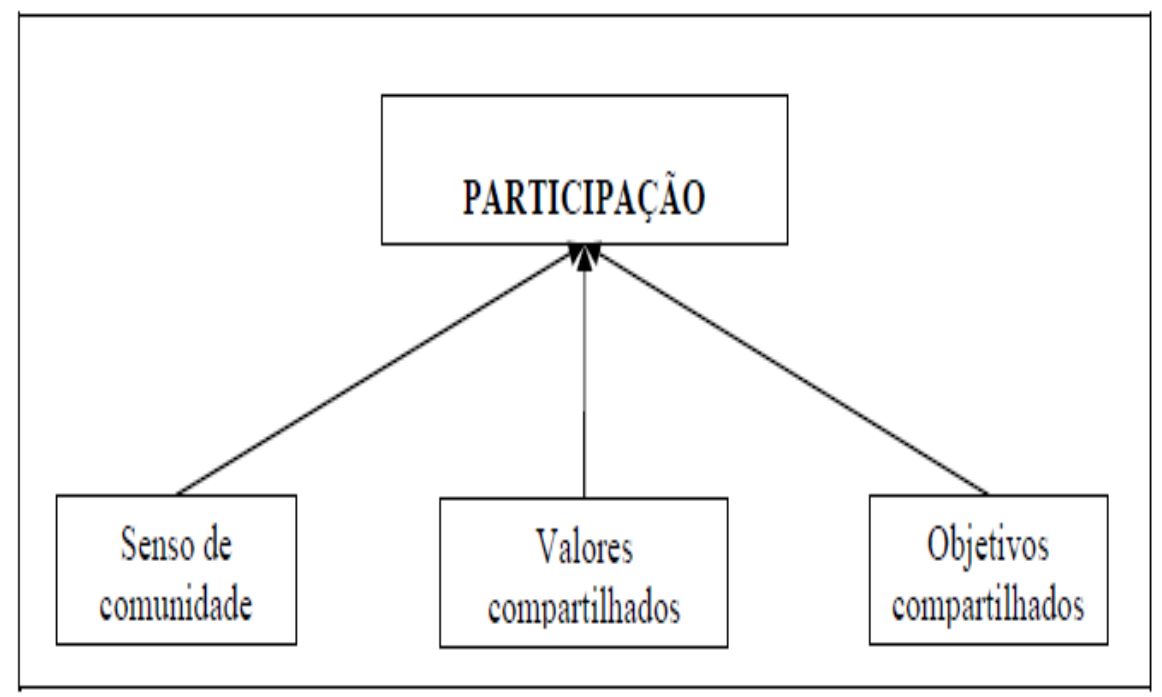

Fonte: BIRCHALL e SIMMONS, 2004 p. 471.

Os fatores que motivam os indivíduos a participar para Birchall e Simmons (2004) são explicados conforme a seguir:

Senso de comunidade é quando o indivíduo se motiva para participar pela semelhança por estar na mesma comunidade, atividade ou por ter afinidades com o grupo. Valores compartilhados é quando o indivíduo se motiva para participar por reconhecimento de necessidades como aumentar a renda, agregar conhecimento, adquirir ou aumentar a infraestrutura. Objetivos compartilhados é quando o indivíduo se motiva para participar por interesses como diminuir custos, competir no mercado e prosperar financeiramente. A abordagem coletivista afirma que quanto mais cada uma destas três variáveis estiver presentes, mais provável será que as pessoas participem.

No entanto, Triandis (1995) segundo Miranda (2002) considera que as abordagens e características do individualismo e do coletivismo como síndromes culturais, as quais define como um modelo qualificado pelo compartilhamento de crenças, atitudes, normas, papeis e valores que são referenciados sobre um tema em regiões geográficas durante um período particular.

Neste sentido, Miranda (2002) define coletivismo como um modelo social que consiste no relacionamento entre indivíduos que se reconhecem como parte do coletivo, considerando a família, a comunidade ou o grupo. Explica que indivíduos, em culturas coletivistas, são motivados por normas e deveres atribuídos pelo coletivo e quando no modelo da cultura individualista esses indivíduos são motivados por suas próprias preferências, necessidades e direitos.

Deve-se considerar que a abordagem individualista, assim como o pensamento individual, é complexo e difícil de ser exteriorizado, podendo ser mais perceptível para entender sobre a inatividade da participação. Por outro lado, a abordagem coletivista, mesmo expondo o individualismo, é vista como mais aceitável de exposição e orienta para entender a adesão e permanência para participação no coletivo. Desta forma as motivações coletivas são dominantes e perfaz uma ferramenta importante de estratégias da participação dos membros para as organizações sociais (BIRCHALL; SIMMONS, 2004). 


\section{Metodologia}

A presente pesquisa possui uma abordagem qualitativa, que de acordo com Creswell (2010, p. 206), "A investigação qualitativa emprega diferentes concepções filosóficos; estratégias de investigação; e métodos de coleta, análise e interpretação dos dados.” Esta abordagem tem características descritivas, pela possibilidade de analisar o objeto, descrevendo o comportamento de características motivacionais das pessoas, contudo sem generaliza-los, ou seja, os resultados são restritos a amostra e para o delineamento da pesquisa, este estudo envolveu ainda, a pesquisa bibliográfica e a pesquisa de campo, definida pela coleta de dados (GIL, 2002).

A pesquisa bibliográfica teve início com uma revisão teórica a partir de pesquisas do autor Johnston Birchall que foi dispersa para outros autores, de forma a expandir o entendimento e assim construir o referencial teórico e os construtos do instrumento para pesquisa de campo. O instrumento utilizado foi o formulário com questões fechadas em escala de 5 pontos, sendo: 1 Discordo totalmente; 2 - Discordo parcialmente; 3 - Não concordo e nem discordo; 4 - Concordo parcialmente; 5 - Concordo totalmente. Foram elaboradas 9 questões afirmativas com base na teoria dos incentivos mutuais na abordagem coletivista de Birchall e Simmons (2004) e mais 3 questões sobre filantropia relacionada com o conceito de organizações sociais, num total de 12 questões, contendo também questões semiabertas e abertas para identificação do tipo de instituição e do papel do membro. Sendo calculada a confiabilidade dessas questões pelo alfa de Cronbach que resultou no valor igual a o, 716, sendo considerado aceito.

A coleta dos dados foi realizada na 8 a edição da maior feira de agronegócio da região norte, a Rondônia Rural Show (RRS), sediada no município de Ji-Paraná, estado de Rondônia, no período de 22 a 25 de maio de 2019. É realizada anualmente desde 2002, pelo Governo do estado, por meio da Secretaria Estadual da Agricultura (Seagri). Foram identificadas 25 cooperativas, sendo 19 no setor de agroindústria familiar, 1 no setor de artesanatos e 5 cooperativas de créditos.

Foram aplicados 19 formulários no setor da agroindústria familiar, pela constatação de ser um segmento promissor no estado em desenvolvimento, mas incipiente em cooperativismo, corroborado pelo espaço cedido específico para estes, contando com 73 expositores de todo o estado e deste total, somente 19 se declararam como membros de organizações sociais, sendo todos entrevistados. Já cooperativas de crédito, estavam presentes 5 instituições, porém, neste setor ocorre o inverso no estado, são fortalecidas, comprovando pela movimentação financeira de 265 milhões de reais em propostas financeiras realizadas durante os quatro dias da feira. Portanto, a pesquisa descreve o fenômeno no setor de agroindústria familiar do estado de Rondônia, embasada nas entrevistas, onde foi possível obter as informações para descrever a percepção dos participantes das organizações sociais.

Complementarmente foi realizado levantamento de dados secundários sobre o setor, e realizado novamente o teste alfa de Cronbach para determinar o nível de confiabilidade (FIELD,2009) dos dados obtidos da aplicação do questionário, depois foram processados e agrupados pelos fatores descritos na teoria obtendo parâmetros percentuais para a criação de tabelas gráficos a partir dos resultados obtidos, o que favoreceu o uso dos valores percentuais para a análise no Excel 2016 e com processamento estatístico no SPSS Statistics 24 (MARÔCO, 2018).

\section{Agroindústria Familiar em Rondônia}

O estado de Rondônia está localizado na porção oeste da região norte do Brasil, com 52

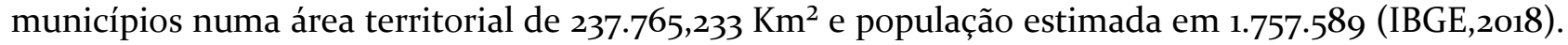
Fortemente estruturado no setor agropecuário, com crescimento elevado desde 2011, porém em 2018 teve resultado de 4,7\% inferior ao obtido em 2017 (EMBRAPA, 2018), mesmo com este resultado as projeções são positivas para os próximos anos, situação ímpar entre a maioria dos estados brasileiros. 
Rondônia tem o terceiro maior PIB da região norte, este posicionamento está diretamente ligado ao agronegócio. O Ministério da Agricultura, Pecuária e Abastecimento (MAPA) aponta que entre os anos (safra) 2016/17 até 2026/27 o estado terá um aumento de 30\% na produção de grãos, que atualmente ocupa o quinto lugar de maior produtor de café e o sétimo do maior rebanho do Brasil (BRASIL, 2017).

O valor do PIB em 2016 foi no valor de R\$ 39 bilhões, desse montante, foi gerado $\mathrm{R} \$ 8,5$ bilhões pela lavoura e pecuária, distribuído em $63 \%$ na pecuária e $37 \%$ na lavoura que concentra a maior parte em quatro culturas de soja, milho, cana-de-açúcar e arroz representando cerca de $25 \%$ desse total. Outro fator importante, é que a cultura do arroz e café, tem como principal destino as agroindústrias de beneficiamento local e a distribuição nos mercados da região (SOUZA, 2019). A Figura 3 mostra os resultados em bilhões gerados pelas lavouras e pecuárias do estado, desde 2010, sendo possível notar a ascensão no setor.

Figura 3 - Gráfico da Renda Agropecuária de Rondônia R\$ bilhões

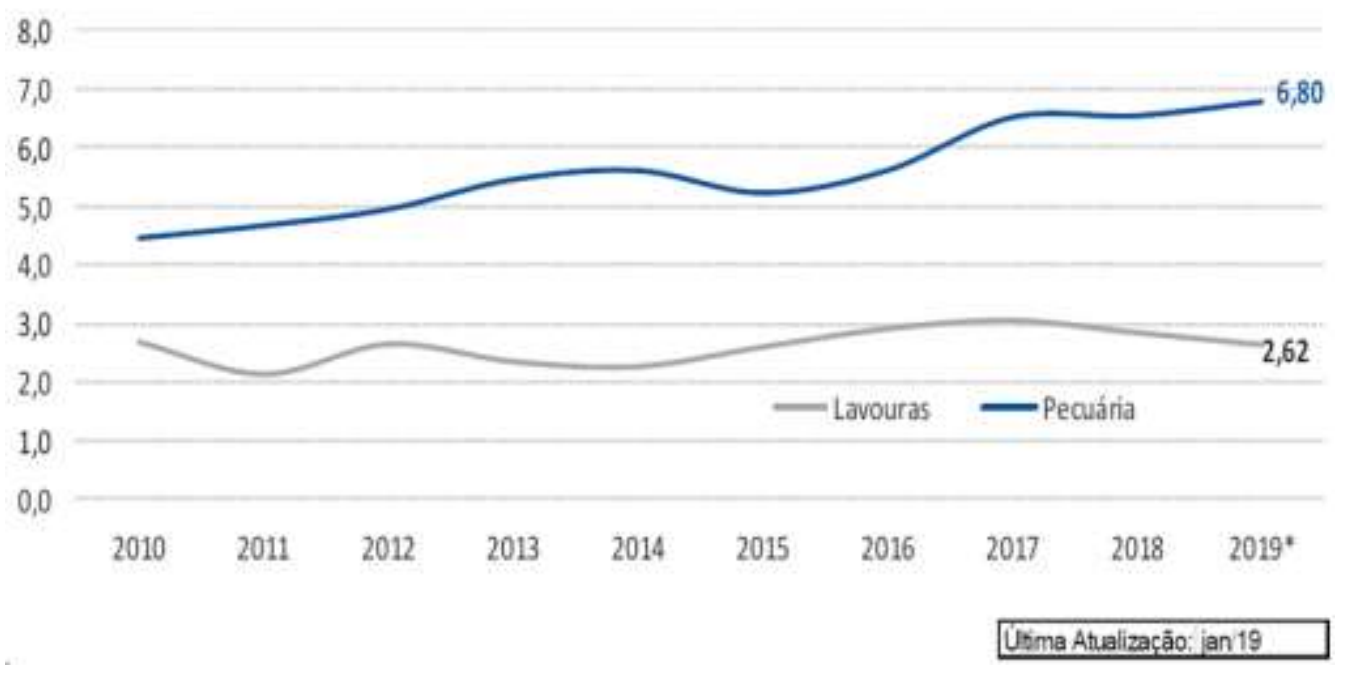

Fonte: Departamento de Pesquisas e Estudos Econômicos - DEPEC, (2019).

É importante salientar os resultados econômicos do agronegócio do estado, para despertar o potencial das agroindústrias. Batalha, (2007) define o agronegócio como a soma total das operações de produção e distribuição de insumos e produtos agropecuários, já a agroindústria são unidades empresariais que transformam os produtos agropecuários in natura até a embalagem (SOUZA, 2019).

O censo agropecuário de 2017, coletados no Sistema do IBGE de Recuperação Automática (SIDRA), dispõe que o número de estabelecimentos agropecuários em Rondônia no ano de 2017 é de 91.437 e o número de estabelecimentos agroindustriais em Rondônia no mesmo ano é de 3.158, demonstrando o quão desproporcional, imaturo e oportuno é o seguimento.

Vislumbrando o potencial e tentando modificar este cenário, principalmente para o pequeno produtor, o governo do estado vem implantando políticas para desenvolver o setor. A primeira foi a criação da Lei Estadual 2.412/11 para implantar o Programa de Verticalização da Pequena Agroindústria Familiar Rural (PROVE), que tem como objetivo principal declarado no Art. $3^{\circ}$ :

Art. 3o O Programa tem como objetivo principal, dentre outros, inserir o pequeno produtor rural no processo produtivo, concedendo-lhe incentivos à produção e ao processamento dos produtos in natura de origem animal e vegetal, de modo a agregar maior valor a estes, aumentando a renda familiar, fixando a família na terra e gerando empregos no campo. 
O Programa PROVE funciona em parceria entre instituições governamentais, organizações não-governamentais, pequenos produtores rurais, suas cooperativas ou associações de que fazem parte. Outra iniciativa do Governo é a divulgação e o fomento desses negócios, através da Rondônia Rural Show. Reflexo dessas iniciativas é o crescimento no número de Unidade Familiares de Processamento Agroindustrial - UFPA, quantificado na Figura 4 e no Quadro 2 detalhado o ano de 2017 por seguimentos e produtos.

Figura 4 - Quantidade de Agroindústrias Familiares no estado de RO.

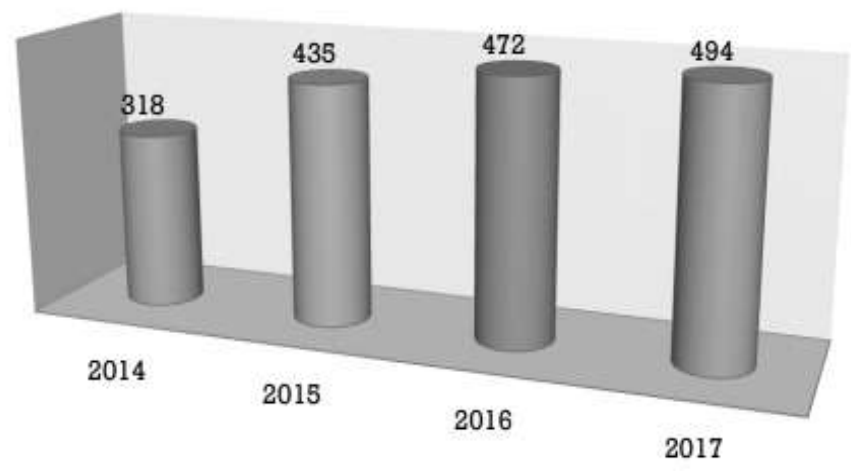

Fonte: EMATER-RO, (2017).

Além disso, é disponibilizado linha de crédito específica, como o PRONAF Agroindústria Programa Nacional de Fortalecimento da Agricultura Familiar e Agroindústria, Fundo Constitucional do Norte (FNO) e de várias organizações sociais com outras linhas de crédito específico.

Fato este, que as agroindústrias obtêm o apoio tanto do governo associado com outras organizações, quanto de cooperativas de crédito para o seu desenvolvimento, mas estas ainda não reconhecem e nem institucionalizaram a importância da cooperação entre elas mesmas, podendo ser observado que num total de 73 unidades agroindustriais familiares, somente 19 faziam parte de cooperativas.

Quadro 2 -Detalhamento de Agroindústrias por Segmentos e Produtos-RO.

\begin{tabular}{|c|c|c|c|}
\hline $\mathrm{N}^{\circ}$ & Segmentos & Tipos de Produtos & Quantidade UFPA \\
\hline 1 & Panificaçâo & $\begin{array}{l}\text { Bolos, tortas, biscoitos, polvilhos, Bombons, } \\
\text { chocolates. }\end{array}$ & 80 \\
\hline 2 & Polpas de Frutas e Bebidas & $\begin{array}{l}\text { "Polpa de Frutas, Água de Coco, Cachaça, } \\
\text { Vinhos, Licor. }\end{array}$ & 92 \\
\hline 3 & Produtos de Origem Animal & $\begin{array}{l}\text { "Cárneos de aves, cárneos de peixe "cárneos } \\
\text { de suinos; cárneos de bovinos; derivados do } \\
\text { leite; logurte, achocolatados; entrepostos de } \\
\text { mel; } \\
\text { Entrepostos de ovos; doce de leite. }\end{array}$ & 193 \\
\hline 4 & Produtos de Origem Vegetal & $\begin{array}{l}\text { Mandioca Minimamente processada; } \\
\text { Derivado do milho; doces (com até } 49 \% \text { de } \\
\text { leite) e geléias; compotas; } \\
\text { Condimentos, frutas cristalizadas; } \\
\text { Cereais processados e misturados; } \\
\text { rapadura; farinha de mandioca. } \\
\text { 'Farinha de babaçu; guaraná em pó; } \\
\text { "Café torrado; leite de Soja; tofu }\end{array}$ & 129 \\
\hline
\end{tabular}

Fonte: EMATER-RO, (2017). 
O cooperativismo é uma filosofia de vida que transforma o mundo com valores de justiça, equilíbrio, felicidade além de oferecer melhores oportunidades para as pessoas, possibilitando o desenvolvimento econômico, social e sustentável de forma produtiva (ORGANIZAÇÃO DAS COOPERATIVAS BRASILEIRAS - OCB, 2019). Apontado como uma alternativa promissora por proporcionar vantagens competitivas, expansão do mercado através da força de ajuda mútua, e que uma parcela pequena no estado atue neste seguimento, principalmente a agroindústria familiar, queremos entender as deficiências da participação através das motivações, visto como fundamental a participação de todos os membros para fortalecer a organização.

\section{Resultados e Discussão}

Nesta seção serão apresentados os resultados da pesquisa que teve como objetivo identificar as motivações dos membros de organizações sociais para participar e continuar ativos como membros.

\subsection{Perfil dos respondentes}

A primeira parte do formulário consistiam em questões semiabertas e abertas para identificar os membros e o tipo da organização, visando compreender a organização social, ramo, localização, quantidade de pessoas filiadas, tempo de criação e o papel do entrevistado na organização. Desta forma, foram identificados dentre os 19 respondentes, 14 participavam de cooperativas e 5 de associações e o papel desses nas organizações, sendo que a maioria ocupavam posto de direção, no total de 13 , representando $68,4 \%$, enquanto que 5 participação somente como membro associado e 1 (um) como funcionário da organização.

Os dados da pesquisa demonstraram que o tempo da organização é bem variável, sendo que alguns respondentes quantificaram como família e outros como pessoas. Sobre as demais características das organizações sociais, a pesquisa demonstrou que: 6 organizações possuem 1 (um) ano de funcionamento e contam com 25 a 30 pessoas filiadas; as 2 (duas) mais antigas, tem o mesmo segmento de produtos de origem animal, mas contam com números de filiados diferentes, enquanto uma tem 31 anos de funcionamento com 230 famílias filiadas, a outra tem 28 anos de funcionamento com 30 famílias filiadas; tem uma que possui mais de 500 pessoas filiadas e tem somente 2 anos de criação; tendo outras 4 , que possuem acima de 200 pessoas filiadas; e 1 (uma) que tem 5 famílias filiadas, a qual está sendo encerrada.

Destaca-se a localização, no estado de Rondônia, das agroindústrias participantes. Abrangeu 12 municípios do Estado, sendo 4 localizadas no município de Vilhena; 3 no município de Ariquemes e 2 no município de Colorado do Oeste e as outras 5 organizações localizam-se em outros municípios do Estado. A produção em sua maioria é no segmento de produtos de origem animal, mas teve organizações dos 4 segmentos (especificados no Quadro 2).

\subsection{Percepção sobre abordagem coletivista}

Outros resultados da pesquisa foram obtidos pelas respostas às questões fechadas, as quais estavam fundamentadas na teoria dos incentivos mútuos com abordagem coletivista, de Birchall e Simmons (2004). Aplicando a primeira dimensão do senso de comunidade, relacionados três fatores: região, ramo/atividade e afinidades. A segunda dimensão refere-se aos valores compartilhados, relacionando três fatores: renda, conhecimento e estrutura. E a terceira dimensão são os objetivos compartilhados, com três fatores: prosperar, competir e custo. Utilizando essas três dimensões através dos 9 fatores buscando identificar o que motiva estes membros a participar da organização. Pontuando que os respondentes em algumas dimensões divergiam sobre duas perspectivas, enquanto respondente na qualidade de direção (administrador) e na qualidade de associado (membro) da organização. 
A Figura 5 demonstra as respostas aos três fatores relacionados na primeira dimensão. $\mathrm{O}$ fator que teve a maior concordância para estes respondentes foram a região, representando 36,8\%, porém este fator também teve o mesmo valor para representar a discordância total, o que poderia anular o fator, mas na junção do concordo totalmente com o concordo parcialmente, este fator se sobressai no valor de $47,3 \%$, entre a mesma junção da discordância, com o valor de $42,1 \%$. Já os fatores de afinidade e atividade foram o mais discordante com um valor de 57,9\% iguais, observando que nesta dimensão a discordância foi maior. Inferindo que este resultado obteve fatores iguais na concordância e discordância, por divergência de posição enquanto função de direção, demonstrando que esses fatores não eram importantes, pois podem participar/associar qualquer pessoa independentemente da localidade, atividade ou afinidade, subentendendo mais como opção da organização e não como motivação própria, determinado o resultado.

Assim, o fator região embora sem grandes relevâncias, como motivador de participação, significando que estar na mesma área é importante para se identificar, constituir um grupo e melhorar sua localidade. $\mathrm{O}$ resultado pode ser explicado porque as pessoas se tornam membros automaticamente em virtude da região geográfica, sendo uma semelhança amorfa (BIRCHALL, 2011).

Outro aspecto que pode ser observado para explicar este resultado é o primeiro princípio da Identidade Cooperativa, a associação voluntária e aberta que expressa que está aberto a todas as pessoas, sem haver discriminação, porém este mesmo salienta que essas pessoas devem ser capazes de usar seus serviços e que desejem aceitar as responsabilidades da associação. Assim nota-se a importância do qualitativo e não somente do quantitativo, pois mesmo que a cooperativa esteja aberta para todos e que quanto mais associados mais forte possa ser, só se fortalecerá se essas pessoas tiverem alguma ligação como o senso de comunidade (região, atividade ou afinidade), fortalecendo o elo e a responsabilidade.

Figura 5 - Gráfico do Senso de Comunidade

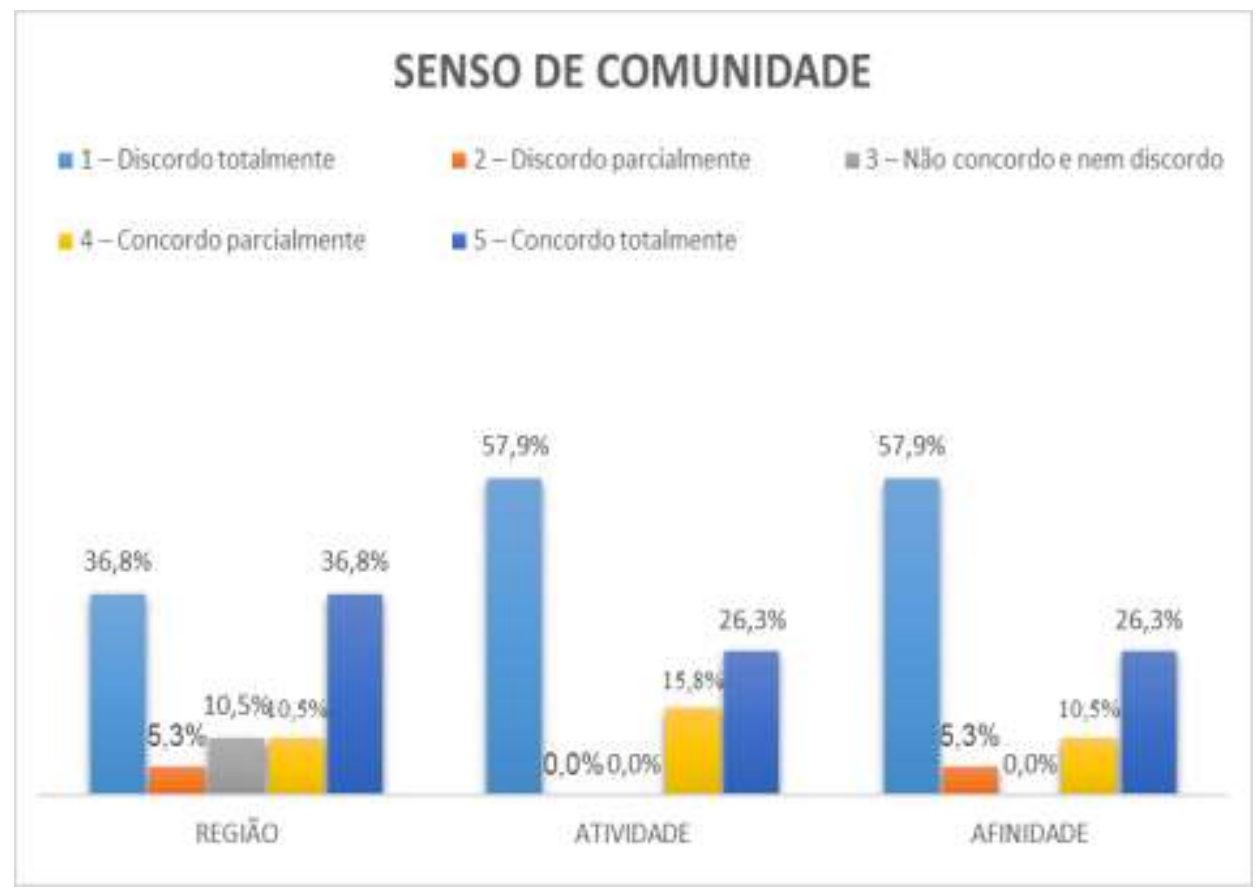

Fonte: Dados da Pesquisa

A Figura 6 demonstra as respostas dos três fatores relacionadas na segunda dimensão da abordagem coletivista, os valores compartilhados. 
Figura 6 - Gráfico dos Valores Compartilhados

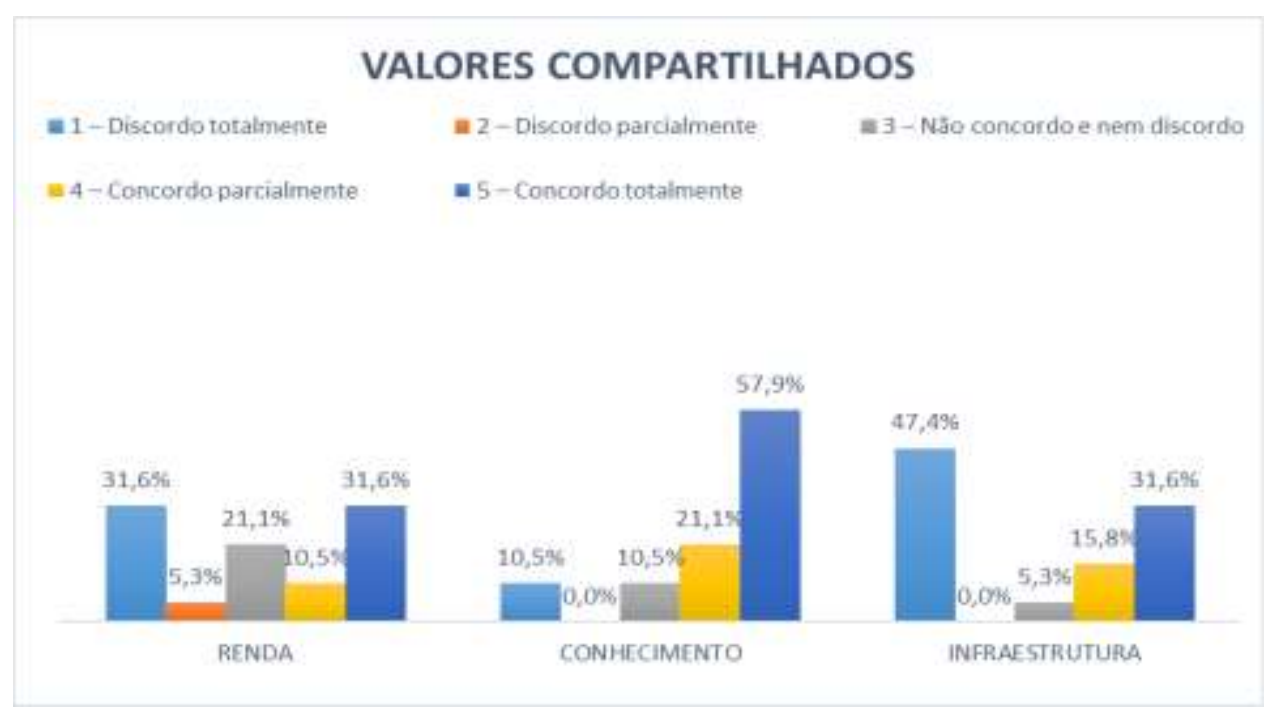

Fonte: Dados da Pesquisa

Esta figura mostra que o fator conhecimento teve a concordância de $57,9 \%$ e o fator infraestrutura o nível de discordância no valor de $47,4 \%$, já o fator renda teve o nível de concordância e discordância em valores iguais de 31,6\%. Então conhecimento na dimensão de valores compartilhados é destacado como o fator mais importante como motivador de participação, o que segundo Giménez e Guitert (200o), entendem este resultado por reciprocidade entre grupos de participantes que transmitem pontos de vistas, experiências e técnicas que constroem conhecimento e distinguem a importância de se aprender mais no grupo do que se aprenderia individualmente (GONÇALVES, 2006).

Ocorre também nesta dimensão, que valores compartilhados é entendido como necessidades compartilhadas, deduzindo que as respostas estavam ligadas com uma necessidade atendida, acusando o fator conhecimento claramente como importante porque é oferecido, porém o fator infraestrutura é a necessidade não atendida na maioria dos respondentes e identificado como um fator de maior interesse, enquanto a renda seria o resultado desses outros fatores, mas não relatado como uma motivação para participar.

Analisando estes resultados pelos princípios da Identidade Cooperativa, possibilita identificar claramente o quinto princípio, a educação, treinamento e informação, confirmando não só a oferta de treinamentos para os membros, como a troca de experiências e conhecimento para que possam contribuir com o desenvolvimento da cooperativa, confirmando a importância e existência do princípio.

A Figura 7 demonstra as respostas dos três fatores relacionadas na terceira dimensão da abordagem coletivista, os objetivos compartilhados. 
Figura 7 - Gráfico Objetivos Compartilhados

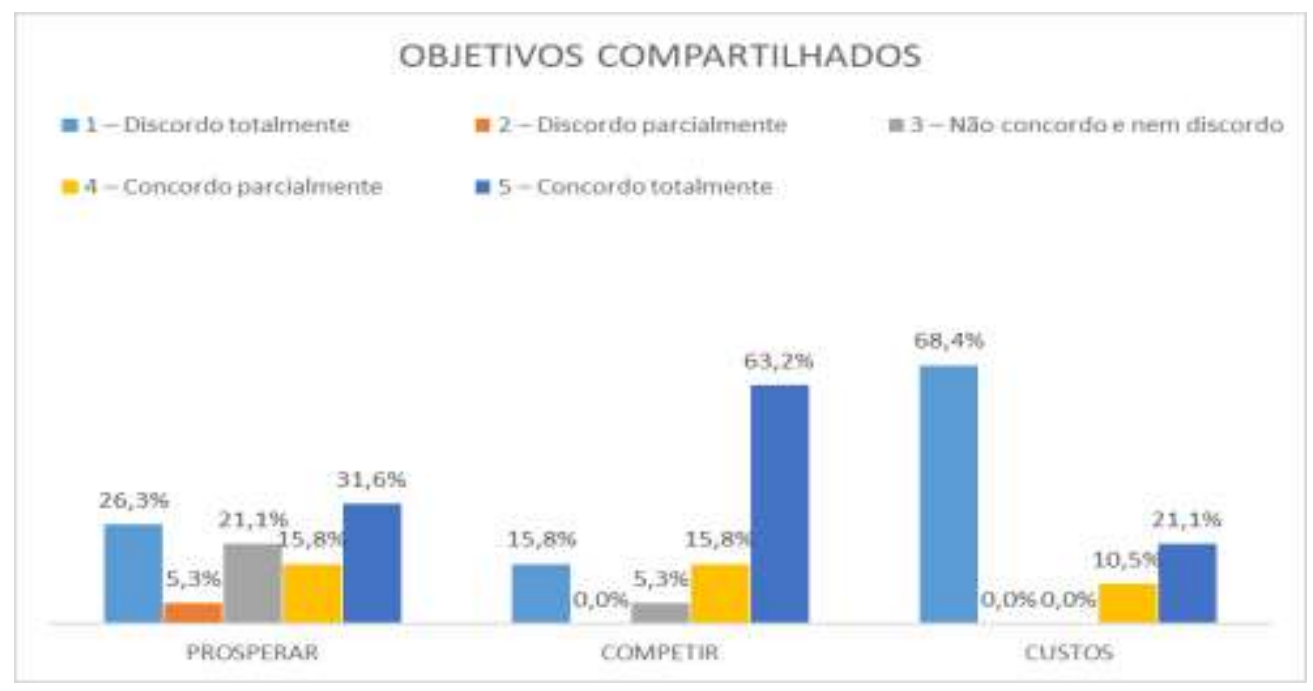

Fonte: Dados da Pesquisa

Aqui se constata que o fator competir foi fortemente percebido, com uma concordância de $62,2 \%$, e o fator custo também com grande relevância de discordância no valor de $68,4 \%$. Assim se compreende que os respondentes reconhecem como motivação da participação são melhores condições para competir no mercado, podendo significar um aumento em suas vendas, porém estes não correlacionaram ou ainda não alcançaram o fortalecimento na competição que resulte no menor custo, ou no aumento das vendas, prosperando financeiramente.

Para entender essa dimensão, reporta-se a Tacussel (1998) para afirmar que as pessoas se associam por interesses comuns, fortalecendo a ideia de comunidade com a união de pessoas por objetivos comuns, fortalecendo a ideia de comunidade com a união de pessoas por objetivos comuns, afirmando que comunidade é uma ligação afetiva de valores e crenças compartilhadas. (GONÇALVES, 2006)

Encontrando assim o segundo princípio da Identidade Cooperativa, o controle democrático dos membros, onde a participação ativa, direta e democrática, estabelece a igualdade de direitos, fortalecendo o grupo que se unem conseguindo alcançar uma fatia maior do mercado tornando-se competitivo.

Desta forma, pode se descrever os fatores que foram percebidos em cada dimensão da abordagem coletivista. Ficando elencado que o local para o senso de comunidade, o conhecimento para valores compartilhados e competir no mercado para objetivos compartilhados. Ter conhecimento dos fatores que motivam os membros a participarem, principalmente pela quantidade de fatores que pode ser identificado em cada dimensão, irá nortear e fortalecer a organização. Tornase importante identificar esses fatores principalmente onde a atuação não é efetiva.

As últimas questões se referem com a variedade de tipos de organizações sociais e como é percebida a filantropia com os membros, a comunidade e fora dela. Objetivando identificar a percepção do membro sobre a organização ser social. 
Figura 8 - Gráfico Filantropia

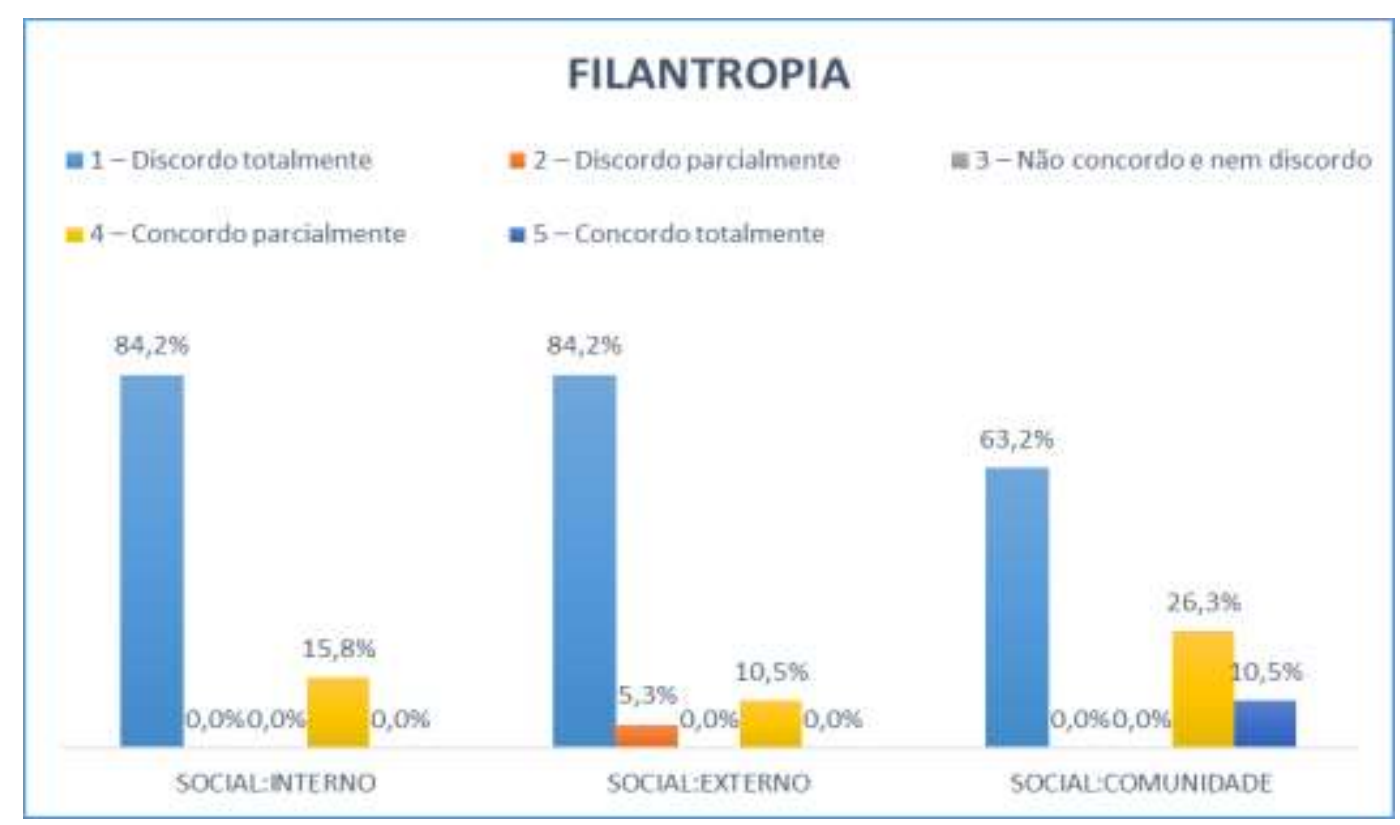

Fonte: Dados da Pesquisa

A Figura 8 revela a predominância na discordância dos três fatores, onde $84,2 \%$ afirmam que as organizações não incentivam a prática de ajuda social no âmbito interno e com o mesmo valor no externo. Já no âmbito da comunidade inserida a discordância é no valor de 63,2\%. Observa-se o desconhecimento sobre o tipo de organização, quando a maioria, inclusive membros diretores, não descreveram como ter ação social entre os membros e comunidade pelo simples fato de estarem constituído em uma organização social. Para Salamon (1998) as pessoas se associam, formando organizações para defender direitos, promover o desenvolvimento econômico local, impedir a degradação ambiental e procurar realizar inúmeros outros objetivos da sociedade, ainda não atendidos, ou deixados sob a responsabilidade do estado (CARRION, 200o). O que torna essas ações sociais pelo simples fato de existência da associação. Exclui-se também o sétimo princípio da Identidade Cooperativa, a preocupação com a comunidade, que estabelece justamente o desenvolvimento sustentável da comunidade onde o grupo está inserido.

Analisando todos os fatores percebidos sob a ótica dos princípios da Identidade Cooperativa, foi possível identificar dois princípios internalizados completamente, sendo os princípios da educação, treinamento e informação, e o controle democrático dos membros, outro princípio empregado, porém parcialmente é o da associação voluntária e aberta, e ainda a exclusão do princípio da preocupação com a comunidade, o que serve para corroborar sobre o enfraquecimento das cooperativas no estado, pois sem diretrizes da sustentação do modelo, pode perder sua caracterização de organização. Mesmo que os sete princípios precisem ser empregados integralmente, no contexto explorado pode ser encontrado somente quatro princípios, porém com a constatação da exclusão e parcialidade de princípios, já consegue-se inculcar para a observação e implantação destes, para caracterizar e fortalecer as organizações analisadas.

\section{Considerações finais}

Organizações sociais vêm progredindo e continua se transformando e reinventando, cogita-se até que seja a melhor forma de se trabalhar atualmente, por associação, cooperando com o grupo e sua comunidade. Muito tem se avançado, mas o comportamento das pessoas continua sendo o maior desafio, fator este que não é exclusivo das organizações sociais, mas de todos os tipos de organizações. 
Enxergar a participação das pessoas pelas perspectivas individual e coletiva se torna uma vantagem competitiva para fortalecer a organização, pois já é sabido que quanto mais participantes efetivos e comprometidos, se reconhecendo como proprietário e responsável pelo crescimento do seu negócio, maiores as chances de sucesso e principalmente de agregar pessoas.

Os interesses e necessidades individuais não precisam ser visto como egocentrismo e sim como motivação pessoal para unir forças e alcançar metas. Além de perceber a atuação das pessoas e qual suas motivações para participar das organizações e reconhecendo que essas organizações são incipientes no estado, foi considerado os princípios da Identidade Cooperativa, que são diretrizes que regem o funcionamento das cooperativas, para ponderar sobre as organizações pesquisadas e não sobre o modelo de organização que já tem fundamentação de ser exemplo de modelo organizacional.

Como sugestão de pesquisas futuras para as organizações sociais da agroindústria de Rondônia, seria verificar o quarto princípio da autonomia e independência, analisando o apoio que o governo do estado oferece e qual sua influência na participação dos membros, onde rumina que a maioria dos participantes se tornam membros, com o único objetivo de conseguir facilidades para financiamentos e assim podendo explicar tanto a motivação como o enfraquecimento das organizações.

\section{Referências}

ALVES, MA. Terceiro setor: as origens do conceito. ENANPAD-Encontro anual da Anpad, v. 26, 2002.

BIRCHALL, J. Towards a social economy, or is it a "Third Sector"? Local Economy: The Journal of the Local Economy Policy Unit, v. 10, n. 2, p. 192-196, 1995.

BIRCHALL, J. Some Theoretical and Practical Implications of the Attempted Takeover of a Consumer Cooperative Society. Annals of Public and Cooperative Economics, v. 71, n. 1, p. 29-53, 2000.

BIRCHALL, J.; SIMMONS, R. WHAT MOTIVATES MEMBERS TO PARTICIPATE IN COOPERATIVE AND MUTUAL BUSINESSES? A theoretical model and some findings. Annals of Public and Cooperative Economics, v. 75, n. 3, p. 465-495, 2004.

BIRCHALL, J. A 'member-owned business' approach to the classification of co-operatives and mutuals. Journal of Co-Operative Studies, v. 44, n. 3, p. 4-15, 2011.

BRASIL. Projeções de Agronegócio 2016/2017 a 2026/2027. Brasília, agosto, 2017. 125p acessado em: 30 de maio de 2019. Disponível: http://www.agricultura.gov.br/assuntos/politica-agricola/todaspublicacoes-de-politicaagricola/projecoes-do-agronegocio/projecoes-do-agronegocio-2017-a-2027versao-preliminar-25-07- 17.pdf

CAEIRO, J. M. C. Economia social: conceitos, fundamentos e tipologia. Revista Katálysis, v. 11, n. 1, p. 61-72, 2017.

CARRION, M.R. Organizações privadas sem fins lucrativos. Tempo Social; Rev. Sociol. USP, v. 12, n. 2, p. 237-255, 2000.

CRESWELL, J. W. Projeto de Pesquisa: métodos qualitativo, quantitativo e misto. 3 ed. Porto Alegre: Armed, 2010. 
DEPEC - Departamento de Pesquisas e Estudos Econômicos. 2019.

EMBRAPA. Sistemas De Produção. 2017.

EMATER. Relatório De Atividades. 2017.

FIELD, A. Descobrindo a estatística usando o SPSS [recurso eletrônico]; tradução Lorí Viali. - 2. ed. Porto Alegre: Artmed, 2009.

GIL, A. C. Como elaborar projetos de pesquisa. 4 ed. São Paulo: Atlas, 2002. p. 41- 57

GONÇALVES, M. I. Comunidade Cooperativa de Aprendizagem em Rede. Senac, p. 50-59, 2006.

GRANOVETTER, M. Economic Institutions as Social Constructions: A Framework for Analysis. Acta Sociologica, v. 35, n. 1, p. 3-11, 1992.

INDALECIO, A.M.A. Participação e a Governança nas Organizações Mutuais. Orientador: Joaquim Rubens Fontes Filho. Dissertação (Mestrado em Administração Pública) - Fundação Getúlio Vargas, Rio de Janeiro, 2010.

ICA. International cooperative alliance statement of cooperative identity. Disponível em:https://ica.coop/en/whats-co-op/cooperative-identity-values-principles. Acesso em 12.nov.2019.

JÚNIOR, M. et al. Gestão nas Organizações do Terceiro Setor: Contribuição para um Novo Paradigma nos Empreendimentos Sociais. EnANPAD, p. 1-16, 2009.

LEVI, Y. 'Local development and co-operatives: none, only one, more than one in the same village', Journal of Co-operative Studies, 1998.

MARÔCO, J. Análise estatística com o SPSS Statistics. $7^{a}$ edição. Gráfica Manuel Barbosa \& Filhos. ISBN: 978-989-96763-5-0, 2018.

MISI, Marcia Costa. Cooperativa de trabalho: direito do trabalho e transformação social no Brasil. São Paulo: LTr, 2000.

MIRANDA, R.O. Cultura Organizacional: um estudo entre as dimensões de individualismo e coletivismo e suas manifestações de horizontalidade e verticalidade. Orientador: Claudio Vaz Torres. Dissertação (Mestrado em Psicologia) - Universidade de Brasília, Brasília, 2002.

Organização das Cooperativas Brasileiras - OCB. Cooperativismo: o que é cooperativismo. Disponível em: https://www.ocb.org.br/o-que-e-cooperativismo. Acesso em: o1.jun. 2019.

PARNELL, E. The Role of Cooperatives and other Self-Help Organizations in Crisis Resolution and Socio-Economic Recovery. OIT, 2002.

PUTNAM, R.D. Making Democracy Work: Civicc Traditions in Modern Italy. Princeton University Press, 1994.

SILVA, M. E. DA; ZEN, A. C. O Contexto Base Da Inovação Rumo À Transição Para a Sustentabilidade: Um Ensaio Sob Uma Perspectiva Complexa. Revista Gestão \& Sustentabilidade Ambiental, v. 3, n. 2, p. 61, 2017. 
SINGER, Paul. A cooperativa é uma empresa socialista. In: Sindicalismo \% Cooperativismo:A economia solidária em debate. São Paulo: UNITRABALHO, 2000.

SOUZA, J. L. Indicadores de Desempenho para a Agroindústria: proposta às insdústrias beneficiadoras de arroz de Rondônia. Orientador: Egon Walter Wildauer. Dissertação (Mestrado em Ciência, Gestão e Tecnologia da Informação) - Universidade Federal do Paraná, Curitiba, 2019.

SCHULZE, E. Estrutura do poder em cooperativas. In: UNISISOS: Perspectiva Econômica. São Leopoldo, 1987. 